\title{
Assembly of Hepatitis C Virus Antigens Expressed from a Recombinant Vaccinia Virus
}

\author{
By Shigeru Yoshida, ${ }^{*}$ Sadao Manabe, ${ }^{*)}$ Osamu Tanishita, ${ }^{*)}$ Chie KajI,*) Yasuyuki Gomi, ${ }^{*)}$ Chisato Mori, ${ }^{*)}$ \\ Akihisa TAKAMIZAWA,*) and Hiroto OKAYAMA**) \\ (Communicated by Masanori OTsukA, M. J. A., April 12, 1996)
}

\begin{abstract}
Recombinant vaccinia viruses that express a full-length Hepatitis $\mathrm{C}$ virus (HCV) genome were constructed. Chimpanzee liver cells were infected with the recombinant viruses and analyzed by electron and immunoelectron microscopy. Three kinds of structures specific to recombinant $\mathrm{HCV}$ vaccinia infection were found in the cytoplasm of the infected cells. They are virus-like particles, clustered particles and high density reticular structures, the latter two of which are often fused together, indicating that they are related each other. Monoclonal antibodies against core, envelope and NS1 and human HCV antisera clearly stained the reticular structures, indicating that at least the reticular structures and perhaps the clustered particles are derived from HCV proteins.
\end{abstract}

Key words: $\mathrm{HCV}$; recombinant vaccinia virus; assembly of $\mathrm{HCV}$ antigens; immunoelectron microscopy.

Introduction. Recent studies on Hepatitis C virus (HCV) have made a rapid progress in our understanding of the structure and function of the $\mathrm{HCV}$ genome ${ }^{1), 2}$ and in clinical diagnosis of $\mathrm{HCV}$ infections. On the bases of similarities of genome structure and processing mode of HCV polyprotein, $\mathrm{HCV}$ has been classified into the family Flaviviridae. ${ }^{3)}$ The approximate size of $\mathrm{HCV}$ was estimated to be 30 to $60 \mathrm{~nm}$ in diameter by polycarbonate membrane filtration. ${ }^{4)}$ It was determined to be 30 to $38 \mathrm{~nm}$ in diameter by filtration through micropore cellulose fibers. ${ }^{5)}$ Virus-like particles of 36 to $62 \mathrm{~nm}$ were detected in the sera of chimpanzees and humans with chronic non-A, non-B hepatitis by electron microscopy. ${ }^{6)}$

The buoyant density of $\mathrm{HCV}$ is $1.10 \mathrm{~g} / \mathrm{ml}^{7,8)}$ and $1.08 \mathrm{~g} / \mathrm{ml}$, which shifts to $1.25 \mathrm{~g} / \mathrm{ml}$ by a detergent treatment. ${ }^{9)}$ The particles with these different densities may correspond to intact virions and nucleocapsid particles, respectively.

Some morphological aspects of HCV have recently been reported. Kaito et al. showed the presence of $55-60 \mathrm{~nm}$ particles with spike-like projections in density fractions of 1.14 to $1.16 \mathrm{~g} / \mathrm{ml}$, which specifically

* Research Foundation for Microbial Diseases of Osaka University, Yahata-cho, Kanonji, Kagawa 768, Japan.

**) Department of Biochemistry, Faculty of Medicine, The University of Tokyo, Hongo, Bunkyo-ku, Tokyo 113, Japan. reacted with the monoclonal antibodies to the putative envelope protein. ${ }^{10)}$ However, the detailed structure of assembled $\mathrm{HCV}$ particles still remains poorly understood mainly because of lack of a cell culture system for efficient virus production and because of inability to obtain an enough quantity from human materials due to a low virus content in HCV-carrier's blood.

A few years ago we initiated an approach to this problem by means of a viral expression vector, which enables high production of foreign proteins. We succeeded in the production of the entire $\mathrm{HCV}$ polyprotein and demonstrated its proper processing in cultured cells. ${ }^{11)}$

In this paper we report at least partial assembly of HCV proteins expressed from recombinant vaccinia viruses in chimpanzee liver-derived cells.

Materials and methods. Cell lines and virus. Chimpanzee liver cell and RK-13 cell lines were cultured as previously reported. ${ }^{11)}$ The vaccinia virus strain $\mathrm{m} 0^{12), 13)}$ was kindly given by Dr. S. Hashizume and propagated in the Eagle's medium supplemented with 5\% fetal bovine serum (FBS) as previously described. ${ }^{11)}$ Chimpanzee liver cells that constitutively produce T7 RNA polymerase were constructed as follows. The DNA fragment containing the T7 RNA polymerase gene was recovered from the plasmid pGT7-6 ${ }^{11)}$ by EcoRI-BamHI digestion followed by 


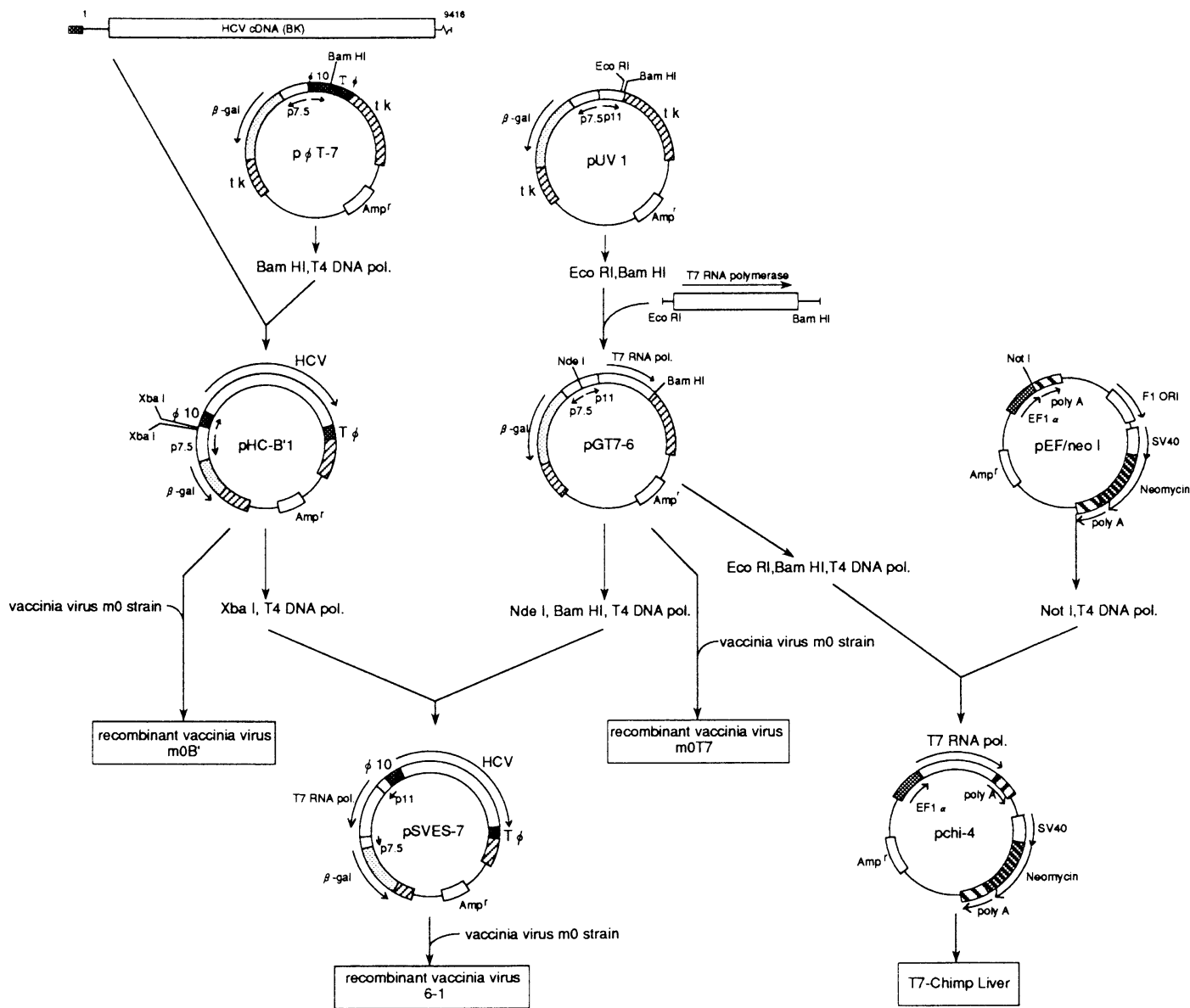

Fig. 1. Establishment of chimpanzee liver cells expressing the T7 RNA polymerase gene and construction of recombinant vaccinia virus containing the T7 RNA polymerase gene and a HCV genome cDNA. The precursor plasmid vector $\mathrm{pEF} /$ neo1, ${ }^{14)}$ which was used for the establishment of chimpanzee liver cells expressing T7 RNA polymerase, contain the EF $1 \alpha$ promoter $(\square)$ and poly A signal $(\mathbf{D S})$, the neomycin gene $(\mathbf{S})$ under the control of the SV40 promoter for screening. The plasmid vector, $p U V 1^{16)}$ and $p \phi T-7$, used for construction of vaccinia virus recombinants, contain the tk gene (एZ) for integration by homologous recombination, the $\beta$-galactosidase (잤) under the control of the vaccinia's p7.5 promoter for screening, and the p11 vaccinia's late promoter or the T7 RNA polymerase-responsive promoter $(\phi 10)(\mathbf{\square})$ and a transcriptional terminator $(\mathrm{T} \phi)(\boldsymbol{\square})$ $\mathrm{Amp}^{\mathrm{r}}$ is the ampicillin-resistant gene.

blunt-ending, and then inserted into the NotI-cut blunt-ended $\mathrm{pEF} /$ neo1 vector ${ }^{14)}$ kindly provided by Dr. S. Nagata (Fig. 1). The resultant T7 RNA polymerase expression vector pchi-4 was transfected into chimpanzee liver cells by calcium phosphate method, ${ }^{15)}$ and some G418-resistant cell clones were isolated. A cell clone T7-chimp liver which constitutively produced a high level of T7 RNA polymerase was selected.

Construction of recombinant vaccinia viruses. The T7 RNA polymerase gene was inserted into the plasmid $\mathrm{pHC}-\mathrm{B}^{\prime}{ }^{11)}$ that had been digested with $\mathrm{Xba \textrm {I }}$ and then blunt-ended. A recombinant vaccinia virus clone called $6-1$, which carried the T7 RNA polymerase gene and a $\mathrm{HCV}$ genome cDNA, was generated by infecting Vero cells with the vaccinia virus $\mathrm{m} 0$ strain followed by transfection with the plasmid DNA as described above. The recombinant vaccinia virus m0T7 and $\mathrm{m}_{0} \mathrm{~B}^{\prime}$ were similarly constructed by in vivo recombination of the $\mathrm{m} 0$ strain with the plasmids pGT7-6 and pHC-B'1, respectively (Fig. 1).

Detection of $\mathrm{HCV}$ proteins expressed from recombinant vaccinia viruses. Chimpanzee liver cells were infected with recombinant vaccinia virus $6-1$ or $\mathrm{m} 0 \mathrm{~T} 7$ at a m.o.i. of 1 and incubated at $32^{\circ} \mathrm{C}$ for $1 \mathrm{hr}$, and virus growth medium Eagle's MEM containing 5\% FBS was added and incubated at $37^{\circ} \mathrm{C}$. The recombinant vaccinia virus m0B' was cultured in chimpanzee 
liver cells constitutively producing T7 RNA polymerase. HCV proteins were detected by Western blot assay as previously described. ${ }^{11}$

Mouse monoclonal antibodies. Mouse monoclonal antibodies against $\mathrm{HCV}$ antigens were prepared and used to detect HCV proteins expressed by recombinant vaccinia virus as previously described. ${ }^{11)}$

Electron microscopy. The recombinant vaccinia viruses-infected cells were collected and pelleted. Cell pellet was fixed with $2 \%$ glutaraldehyde in $0.1 \mathrm{M}$ cacodylate buffer $\left(\mathrm{pH} \mathrm{7.2)}\right.$ at $4^{\circ} \mathrm{C}$ for $1 \mathrm{hr}$ and then with $2 \%$ osmium tetroxide in $0.1 \mathrm{M}$ cacodylate buffer $(\mathrm{pH}$ $7.2)$ at $4^{\circ} \mathrm{C}$ for $1 \mathrm{hr}$. The fixed cells were dehydrated with graded ethyl alcohol and embedded in Quetol 812 resin (Nisshin EM Co. Ltd., Japan). Ultrathin sections made were stained with $2 \%$ uranylacetate and Reynold's lead citrate and examined with an H-7000 Hitachi transmission electron microscope. For immunoelectron microscopy, the recombinant vaccina viruses-infected cells were fixed with $4 \%$ paraformaldehyde containing $0.2 \%$ glutaraldehyde in $0.1 \mathrm{M}$ phosphate buffer $(\mathrm{pH} 7.3)$ at $4^{\circ} \mathrm{C}$ for $2.5 \mathrm{hr}$ and washed well with $0.1 \mathrm{M}$ phosphate buffer ( $\mathrm{pH}$ 7.3). The fixed cells were dehydrated with ethyl alcohol as described above, embedded in LR White resin (London Resin Co. Ltd., United Kingdom) and polymerized by an exposure to ultraviolet light at room temperature for $72 \mathrm{hr}$. The ultrathin sections were treated with mouse monoclonal antibodies or $\mathrm{HCV}$ carrier's serum at $4^{\circ} \mathrm{C}$ overnight, and then with gold-labeled anti-mouse IgG (Amersham International plc., England) or goldlabeled anti-human IgG (Amersham International plc., England) at $37^{\circ} \mathrm{C}$ for $1 \mathrm{hr}$. The ultrathin sections were then doubly stained with uranyl acetate and lead citrate as mentioned above and examined with a Hitachi transmission electron microscope.

Results. Expression of $\mathrm{HCV}$ proteins from high production recombinant vaccinia viruses. To obtain high level production of HCV proteins, the recombinant vaccinia virus $6-1$ carrying both the bacterial T7 RNA polymerase transcriptional unit and the entire HCV polyprotein transcriptional unit driven by a T7 phage promoter was constructed and infected into chimpanzee liver cells. Lysate of the infected cells was analyzed by Western blot assay using mouse monoclonal antibodies. All the expected HCV proteins were produced as previously described, ${ }^{11)}$ which were 22 $\mathrm{kDa}$ core, $32 \mathrm{kDa}$ envelope, 53 to $58 \mathrm{kDa} \mathrm{NS} 1,65 \mathrm{kDa}$ NS3, $7 \mathrm{kDa}$ NS4a, $52 \mathrm{kDa}$ NS5a and $58 \mathrm{kDa}$ NS5b proteins, respectively. These $\mathrm{HCV}$ proteins were

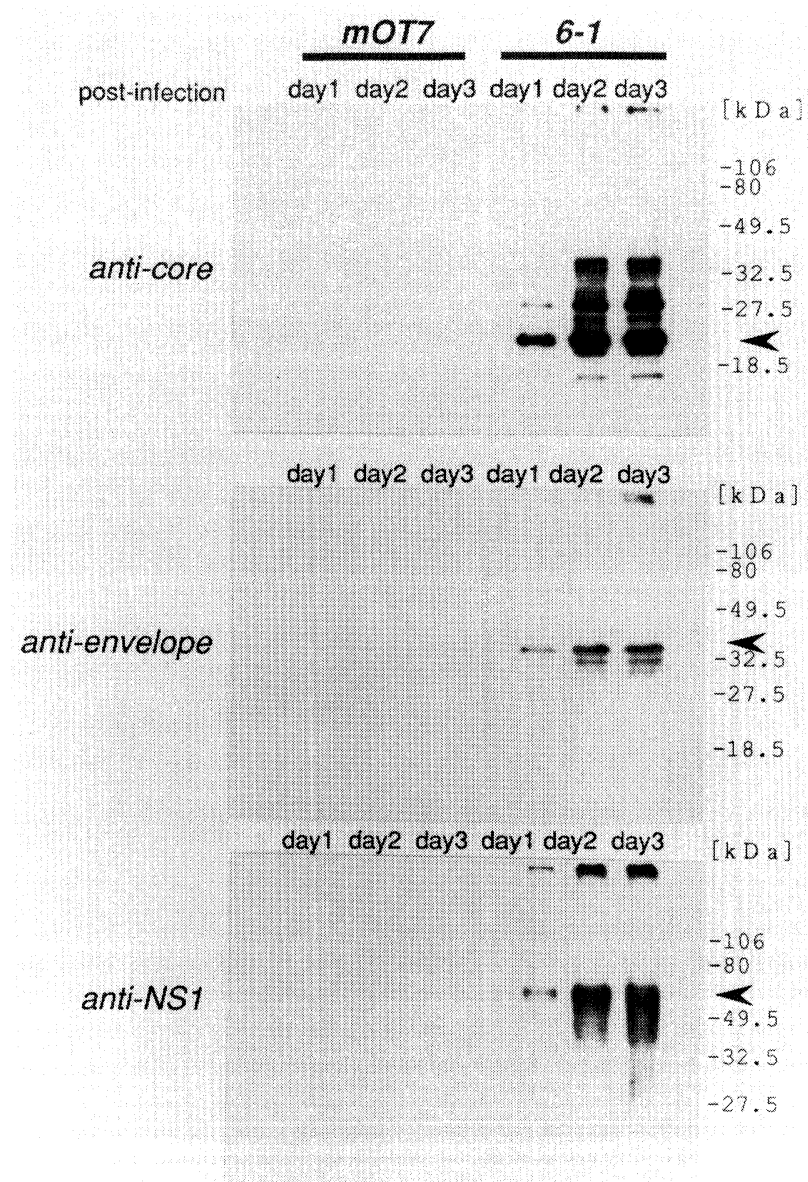

Fig. 2. Time-dependent expression of HCV structural proteins. HCV proteins expressed in chimpanzee liver cells following infection with recombinant vaccinia viruses were analyzed by Western blot assay. The arrows indicate the main band of core, envelope and NS1 proteins, respectively. Cells were infected as described in Materials and methods. The extract from the cells infected with recombinant vaccinia virus $\mathrm{m} 0 \mathrm{~T} 7$ and $6-1$ were prepared day 1, day 2 and day 3 after infection. Each sample was electrophoresed in a polyacrylamide gel containing $0.1 \%$ SDS and blotted to a nitrocellulose filter. HCV proteins were detected by immunoblotting with anti-core, envelope and NS1 monoclonal antibodies.

indistinguishable in molecular size from those expressed from the recombinant vaccinia viruses RVVB' and RVV-T7 which carries the HCV genome cDNA and the T7 RNA polymerase gene. ${ }^{11)}$ Furthermore, these HCV proteins were expressed and processed or degraded in a time-dependent manner, yielding many extra bands (Fig. 2).

Production of HCV-related structures in the cells infected with recombinant vaccinia viruses. The ultrathin section specimens embedded in Quetol 812 resin were examined with an electron microscope, 


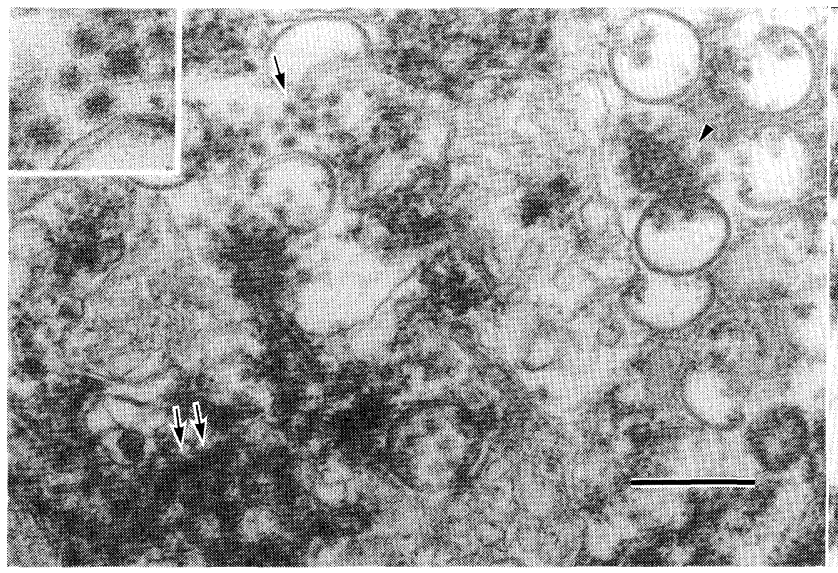

$(\mathrm{A}-1)$

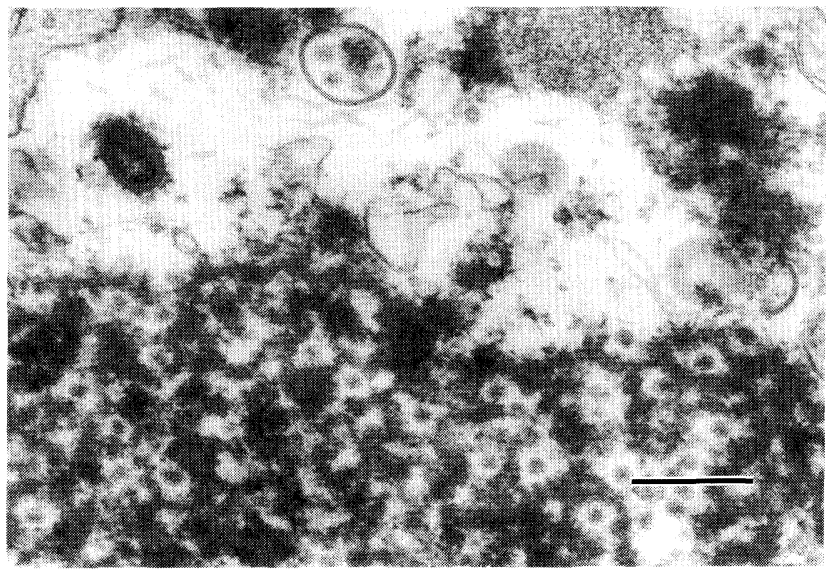

(B)

Fig. 3. Electron micrographs of an ultrathin section of recombinant $\mathrm{HCV}$ vaccinia virus infected chimpanzee liver cells. (A-1, A-2) The recombinant vaccinia virus 6-1-infected chimpanzee liver cells. In the (A-1), the particles (indicated by an arrow), clustered particles (indicated by a closed triangles), and reticular structures (indicated by double arrows) were contained in the cytoplasm, 3 days after infection with the recombinant vaccinia virus $6-1$. The upper left inset in (A-1) indicated the magnified image of the virus-like particles that were 80 to $90 \mathrm{~nm}$ in diameter with a envelope-like layer on the surface. (B)T7 RNA polymerase producer chimpanzee liver cells infected with recombinant vaccinia virus m0B'. The virus-like particles were identified in high density reticular structures 3 days after infection. The scale bars represent $500 \mathrm{~nm}$.

which resulted in the detection of reticular structures and virus-like particles with relatively high electron density in addition to immature or mature vaccinia virus particles (Figs. 3A-1, 2). The reticular structure varied in size and spreaded in the cytoplasm.

The size of the virus-like particles was approximately 80 to $90 \mathrm{~nm}$ in diameter. These particles were

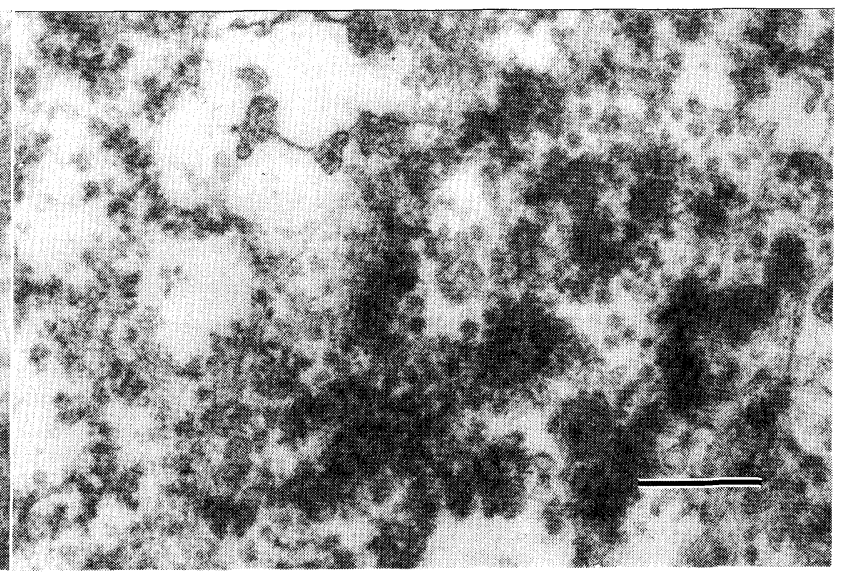

(A-2)

found in immature shells of vaccinia viruses or in their vicinity. Particles often clustered. However, clusters were infrequent and were detected only late postinfection, mostly on day 3 . On the surface of the particles, a thin envelope-like structure was attached.

The time-dependent production of those structures was shown in Table I. The production of each structure increased with time, coinciding well with the increase in the production of $\mathrm{HCV}$ proteins as detected by Western blot (Fig. 2). None of these structures was detectable in m0T7-infected cells. m0T7-infected cells rarely contained slightly resembling particles.

$\mathrm{HCV}$ proteins were also expressed from another recombinant vaccinia virus $\mathrm{m} 0 \mathrm{~B}^{\prime}$ in cells which stably produced T7 RNA polymerase. In this infection system, HCV proteins were expected to be produced from the early stage of viruses infection. Electron microscopy of ultrathin sections of recombinant vaccinia virus m0B'-infected T7-chimp liver cell line cultures showed the same virus-like particles and reticular structures as observed in recombinant vaccinia virus 6 -1-infected cells. The virus-like particles were also within the reticular structures and often fused each other, suggesting that the particulate structures are derived from the reticular structures (Fig. 3B). These particles were not homogeneous in size but highly similar to those detected in the recombinant vaccinia virus 6-1-infected cells, particularly in surface structure and electron density.

Detection of HCV proteins by immunoelectron microscopy. Indirect immunogold electron microscopy was performed to further examine the structures. Mouse monoclonal antibodies and human HCV antiserum as primary antibodies were used as probes, together with gold particle $(10 \mathrm{~nm})$ labeled anti-IgG as 
Table I. Time-dependent production of HCV-related structures

\begin{tabular}{lrrrr} 
& Particles & $\begin{array}{c}\text { Clustered } \\
\text { particles } \\
\text { Post-infection }\end{array}$ & $\begin{array}{c}\text { Reticular } \\
\text { structures } \\
\text { [ visual fields in } 6-1 \text { infected cells } / \\
\% \text { visual fields in m0T7 infected cells }]\end{array}$ & Vaccinia \\
\hline Day 1 & $3 /<1$ & $<1 /<1$ & $2 /<1$ & $80 / 88$ \\
Day 2 & $18 /<1$ & $<1 /<1$ & $12 /<1$ & $86 / 91$ \\
Day 3 & $38 / 1.1$ & $3 /<0.4$ & $31 / 0.4$ & $91 / 98$ \\
\hline
\end{tabular}

The frequencies of the presence of vaccinia particles, virus-like particles, clustered particles and reticular structures were calculated by counting the number of these structures in electron micrographs of different visual fields taken at random with a 45000 fold magnification at day 1 , day 2 and day 3 after infection with recombinant vaccinia virus $6-1$ or the control recombinant vaccinia virus m0T7. The numbers of micrographs examined are 105-140 for day 1, 105-120 for day 2 and 279-280 for day 3.

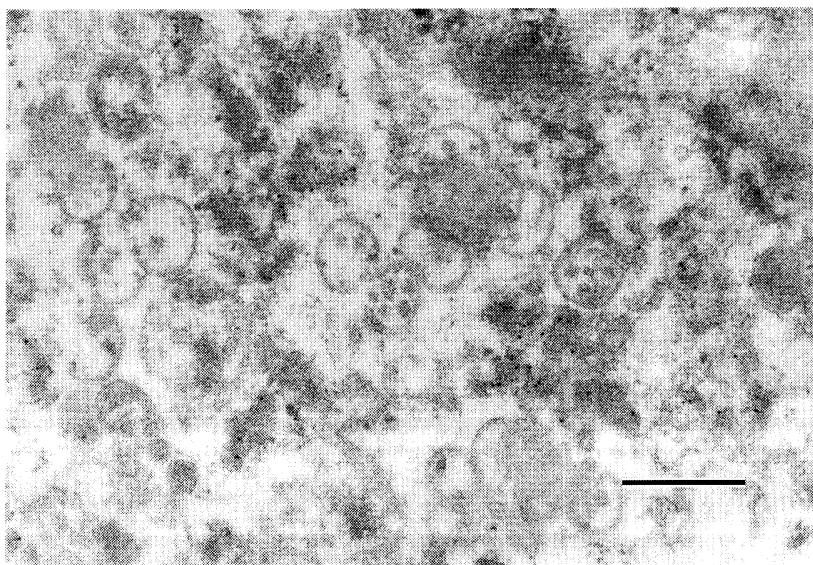

(A)

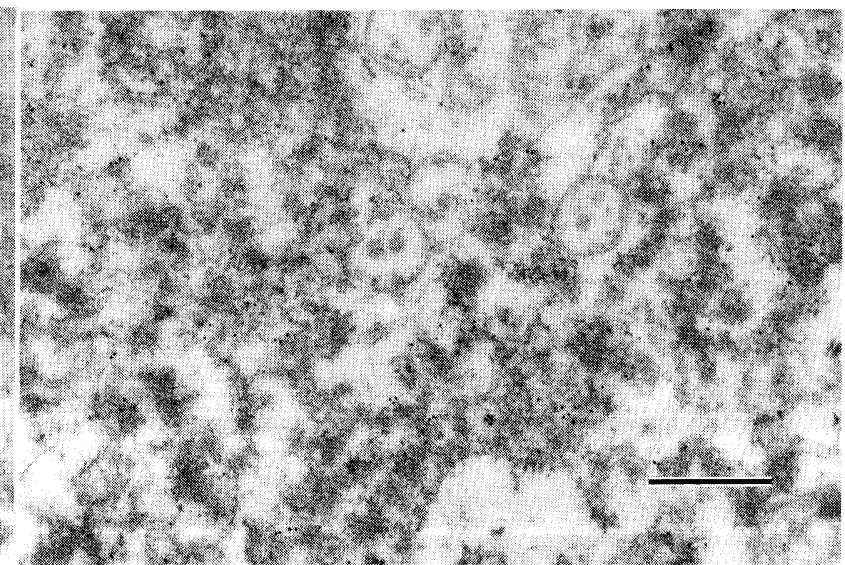

(B)

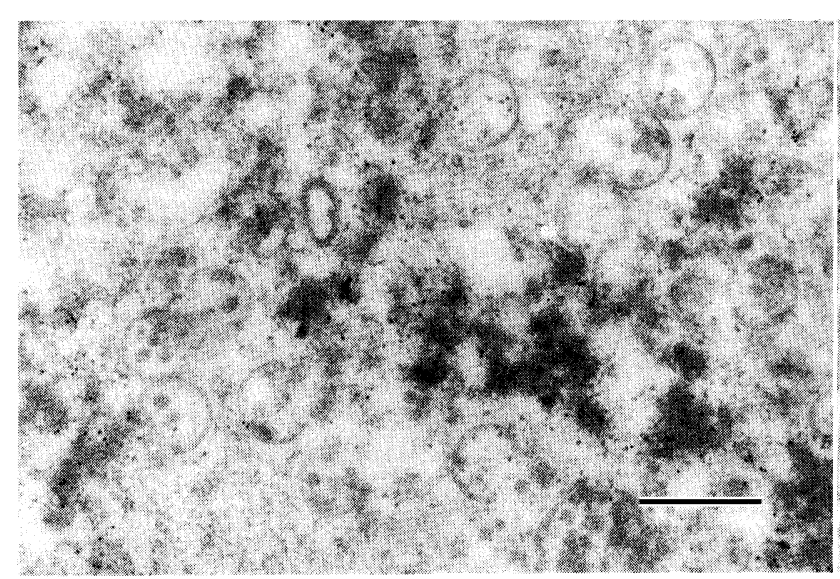

(C)

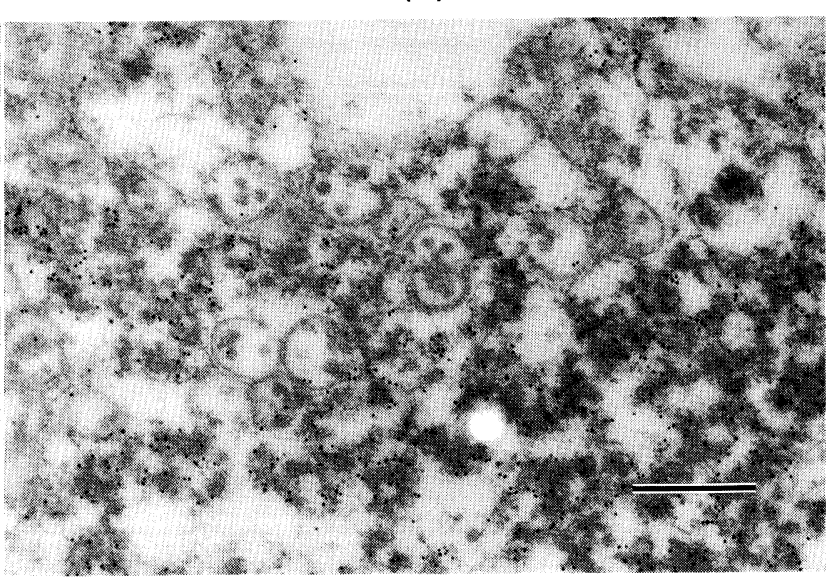

(D)

Fig. 4. Immunoelectron micrograph of recombinant vaccinia virus 6 -1-infected chimpanzee liver cells. The recombinant vaccinia virus infected chimpanzee liver cells were incubated for 2 days and then treated with anti-core (A), anti-envelope (B), anti-NS1 (C) mouse monoclonal antibodies and HCV patient serum (D). Reacted antibodies were detected by binding to goat anti-mouse IgG (A), (B), (C) and goat anti-human IgG (D) conjugated with colloidal gold particles $(10 \mathrm{~nm})$. The scale bar represents $500 \mathrm{~nm}$. 
secondary antibodies for visualization.

Human HCV antisera relatively strongly reacted with the reticular structures. In some photos, clustered particles in vaccinia shell or in its vicinity were stained with the antibody albeit rarely.

Monoclonal antibodies to the HCV core antigen reacted with the reticular structure (Fig. 4A). Similarly, monoclonal antibodies to $\mathrm{HCV}$ envelope, NS1 reacted with the reticular structures but to a much less extent (Figs. 4B, C). Thus, the monoclonal antibodies used are less potent than the human HCV antisera (Fig. 4D). Perhaps partly because of this low potency, none of the monoclonal antibodies were able to staine the particles or clustered particles. None of human $\mathrm{HCV}$ antisera, monoclonal anti-core, envelope or NS1 antibodies reacted with recombinant vaccinia virus m0T7-infected cells.

Discussion. In this paper, we report that $\mathrm{HCV}$ proteins expressed in a high level by a vaccinia-based expression vector are assembled into visible structures including virus-like particles, which appeared in a time-dependent manner, in a good correlation with the production of $\mathrm{HCV}$ proteins.

One visible structure detected is the reticular structure which contains HCV proteins as demonstrated by immunostaining. This structure seems to be a precursor or an assembling intermediate for the viruses-like particles or their clusters since they were often physically linked to the reticular structure, specific to recombinant vaccinia virus-infected cells, and tended to be formed after the formation of the reticular structure. We, however, failed to definitively show that the particles contain HCV proteins by immunoelectron micrography. This failure may be attributable partly to low sensitivity of the antibodies used and partly to the inability of antibodies to access antigenic epitope(s) after proteins have fully or nearly fully been assembled.

The particles produced in the recombinant vaccinia virus-infected cells are $80-90 \mathrm{~nm}$ in diameter, a size slightly larger than, but their morphology is strikingly similar to, those reported recently. ${ }^{10)}$ The particles contain an envelope-like surface with spike-like structures. Although the size is slightly larger, the structural similarity further indicates that the virus-like particles produced from the recombinant vaccinia viruses are indeed assembled HCV proteins. Since high production of HCV in cell culture is not available, the recombinant vaccinia system may prove to be an effective way to obtain a relatively large amount of HCV-related particles to study the structure and assembly of $\mathrm{HCV}$.

Acknowledgment. We thank to Dr. Kunihiko Hino (School of Medicine National Defence Medical College) for kindly supplying human HCV antisera.

\section{References}

1) Kato, N., Hijikata, M., Ootsuyama, Y., Nakagawa, M., Ohkoshi, S., Sugimura, T., and Shimotohno, K. (1990) Proc. Natl. Acad. Sci. U.S.A. 87, 9524-9528.

2) Takamizawa, A., Mori, C., Fuke, I., Manabe, S., Fujita, J., Onishi, E., Ando, T., Yoshida, I., and Okayama, H. (1991) J. Virol. 65, 1105-1113.

3) Wengler, G. (1991) In Classification and Nomenclature of Viruses (eds. Francki, R. I. B., Fauguet, C. M., Knudson, D. L., and Brown, F.). Arch. Virol., Suppl. 2, Springer Verlag, Wien, pp. 223-233.

4) He, L-F., Alling, D., Popkin, T., Shapiro, M., Alter, H. J., and Purcell, R. H. (1987) J. Infect. Dis. 156, 636-640.

5) Yuasa, T., Ishikawa, G., Manabe, S., Sekiguchi, S., Takeuchi, K., and Miyamura, T. (1991) J. Gen. Virol. 72, 2021-2024.

6) Abe, K., Kurata, T., and Shikata, T. (1989) Arch. Virol. 104, 351-355.

7) Bradley, D. W., Maynard, J. E., Popper, H., Cook, E. H., Ebert, J. W., McCaustland, K. A., Schable, C. A., and Fields, H. A. (1983) J. Inf. Dis. 148, 254-265.

8) Bradley, D., McCaustland, K., Krawczynski, K., Spelbring, J., Humphrey, C., and Cook, E. H. (1991) J. Med. Virol. 34, 206-208.

9) Miyamoto, H., Okamoto, H., Sato, K., Tanaka, T., and Mishiro, S. (1992). J. Gen. Virol. 73, 715-718.

10) Kaito, M., Watanabe, S., Kohara, K., Yamaguchi, K., Kobayashi, Y., Konishi, M., Ishida, S., Suzuki, S., and Kohara, M. (1994) J. Gen. Virol. 75, 1755-1760.

11) Manabe, S., Fuke, I., Tanishita, O., Kaji, C., Gomi, Y., Yoshida, S., Mori, C., Takamizawa, A., Yoshida, I., and Okayama, H. (1994) Virology. 198, 636-644.

12) Sugimoto, M., and Yamanouchi, K. (1994) Vaccine. 12, $675-681$.

13) Hashizume, S., Yoshikawa, H., Morita, M., and Suzuki, K. (1985) In Vaccinia Viruses as Vectors for Vaccine Antigens (ed. Quinman, G. V.). Elsevier, Amsterdam, pp. 87-99.

14) Mizushima, S., and Nagata, S. (1990) Nucleic Acids Res. $18,5322$.

15) Graham, F. L., and van der Eb, A. J. (1973) Virology. 52, 456-467.

16) Falkner, F. G., Chakrabarti, S., and Moss, B. (1987) Nucleic Acids Res. 15, 7192. 